American Journal of Agricultural and Biological Science 3(1): 325-329, 2008

ISSN 1557-4989

(C) 2008 Science Publications

\title{
Compressive Load Resistance Characteristics of Rice Grain
}

\author{
${ }^{1}$ Sumpun Chaitep, ${ }^{1}$ Chaiy Rungsiyakull and ${ }^{2}$ Pipatpong Watanawanyoo \\ ${ }^{1}$ Mechanical Engineering Department, Faculty of Engineering, Chiang Mai University, Thailand 50200 \\ ${ }^{2}$ College of Engineering, Rangsit University, Thailand 12000
}

\begin{abstract}
Investigation was made to observe the compressive load property of rice gain both rough rice and brown grain. Six rice varieties (indica and japonica) were examined with the moisture content at $10-12 \%$. Compressive loads with reference to a principal axis normal to the thickness of the grain were conducted at selected inclined angles of $0^{\circ}, 15^{\circ}, 30^{\circ}, 45^{\circ}, 60^{\circ}$ and $70^{\circ}$. The result showed the compressive load resistance of rice grain based on its characteristic of yield strength, of which can be expressed as relationships of the shear strength. Two similar experiments, both parallel and cross grain positions were conducted on the rough rice and brown rice. Result showed the trend of load resistance of rice grain, which may be used as an important parameter for the design of related post-harvest machines. The properly designed machine in conjunction with this compressive strength might lead to the minimal use of power consumption of the machines as well as lowering the broken rice during the rice mill processes.
\end{abstract}

Keywords: Rough rice, Brown rice, Shear resistance of rice, Compressive load. Principal axis.

\section{INTRODUCTION}

Thailand is one of an agro-based industrial country, reflected by the portion of more than $57 \%$ arable land is utilized as paddy field for rice production ${ }^{[1]}$. For the period from 1977 to 1981 , the annual tonnage exportation of rice was from 1.6 to 3.0 million tones with annual income of 10 to 26 trillion baht ${ }^{[2]}$. Compare to the period from 1982 to 1987 that annual export was increased from 3.5 to 4.6 million tones with annual income escalated from about 20 to 26 trillion bath, respectively (at 25 bahts to 1 US dollar). The aforementioned tonnages exported were all either white rice or parboil-rice. A recent investigation of postharvest for assessment the loss of rice during the ricemill process which were divided into 4 successive sub processes: de-husking, cleaning, whitening or polishing and sorting ${ }^{[3]}$. It was revealed that total loss were ranged, depended upon the size of rice-mill, from 16\% of the large rice-mill compare to an excessively high loss of $43 \%$ in the small size mill. A surmountable loss of revenue from rice processing is quite certain due to the amount of broken rice, which after sorted out, has to sell at less value as animal feed supplement. One main goal to minimal loss as broken rice can be achieved by maintaining a proper operation of machines concerned in the rice-mill processing. Of which the physical properties and grain characteristics, especially the compressive load resistance to the break point is a prime parameter necessary to be investigated for further improvement of rice processing machines.

Rice: Rice is a grass family of Graminea. It is an herbaceous or non-woody plant. Most varieties are annual grass with monocotyledon and have fibrous root system. Grows well in the tropical zone but some varieties can grow in the temperate zone. Wild rice has found in the region from $53^{\circ} \mathrm{N}$ latitude to $35^{\circ} \mathrm{S}$ latitude and at any elevation from sea level to $1,800 \mathrm{~m}$ (Mean sea level). Rice is one of the world most important cereal crops; it is adaptive to variation of both climate and geographical. Rice can also be divided into 2 types according to the property of starch, i.e., non-glutinous (or non-waxy) rice and glutinous (or waxy) rice. The non-glutinous rice composes of two-carbohydrate type Amylose and Amylopectin of $30 \%$ and $70 \%$ respectively. Whereas the glutinous rice is almost $100 \%$ Amylopectin, hence offer a sticky property when being cooked $^{[4]}$. Generally the dimension of a rice grain can be expressed in 3-dimension ${ }^{[5]}$ by length characteristics of the grain length (L), the grain width (W) and the grain thickness (T). Occasionally may also supply with the length of awn or beard (h). Figure 1 shows the dimensions of rice grain.

Corresponding Author: $\quad$ Sumpun Chaitep, Mechanical and Agricultural Engineering Department, Faculty of Engineering, Chiang Mai University, Thailand 50200, Tel: (66 53) 942005, Fax: (66 53) 942062 


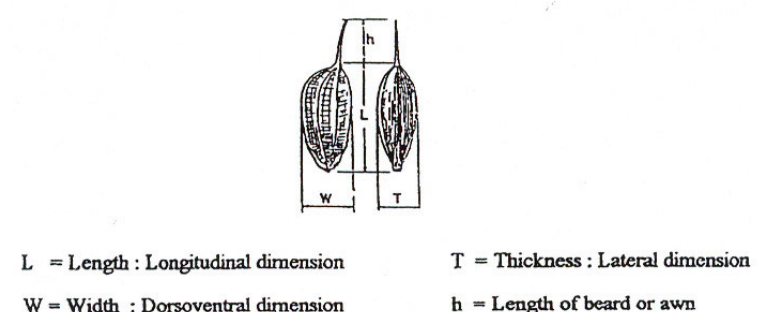

Fig. 1: Defined dimension of rice ${ }^{[5]}$

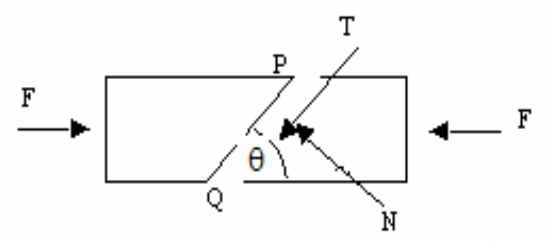

Fig. 2: Normal and shear stresses

Stress theory: Stress is the internal reaction resistance of material against the external force that applies to the body of material. Theoretically the reaction force is equal and opposite to the external applying load. Various materials have different capacity of maximum load resistance. The maximum load can be considered at the point of permanent dislocation of the material, that after the withdrawal of external load, whereby the material cannot returns to its original shape. Stress is expressed as the external force that applies to the material per unit area of the material perpendicular (or parallel) to the force. Two types of stress depend upon the direction of applied load, i.e., 1). Compressive stress is relying on the load that pushing to compact the material, or 2). Tensile stress that rely on the load that pulling, in the sense, to elongate the material

Consider an example to define the normal stress on a cylindrical solid specimen (Fig. 2). Assume that a uniformly distributed load occurs to the whole cross sectional area $\mathrm{A}$ of the material. Therefore, the normal stress perpendicular to the external load $\mathrm{F}$ is

$$
\sigma_{\mathrm{no}}=\frac{\mathrm{F}}{\mathrm{A}}
$$

If only the normal stress exist to the plane perpendicular to the load, it can then be called that stress as the principal stress.

However, if further consider at any arbitrary inclined plane PQ to the principal stress. Let this inclined plane situated at an angle of $\theta$, then the normal force component $(\mathrm{N})$ and the tangential force component $(\mathrm{T})$ are

$$
\mathrm{N}=\mathrm{F} \sin \theta
$$

and $\mathrm{T}=\mathrm{F} \cos \theta$

$\mathrm{T}$ can also be defined as shear force along the inclined plane PQ.

The inclined surface area cut by the plane PQ has the value of $\mathrm{A} / \sin \theta$. Let this inclined plane has normal stress as $\left(\sigma_{\mathrm{n} \theta}\right)$ and the shear stress as $\left(\tau_{\theta}\right)$ Hence following relations express

$$
\begin{aligned}
& \sigma_{\mathrm{n} \theta}=\frac{\mathrm{N} \sin \theta}{\mathrm{A}}=\frac{\mathrm{F}}{\mathrm{A}} \sin ^{2} \theta \\
& \tau_{\theta}=\frac{\mathrm{T} \sin \theta}{\mathrm{A}}=\frac{\mathrm{F}}{2 \mathrm{~A}} \sin 2 \theta
\end{aligned}
$$

Inspecting these two equations, concluded that maximum $\left(\sigma_{\mathrm{no}}\right)$ is the $\mathrm{F} / \mathrm{A}$ while the maximum $\left(\tau_{\theta}\right)$ is the differentiation of equation (5) with respect to $\theta$ and equate to zero.

$$
\begin{aligned}
& \text { Hence } \frac{\mathrm{d} \tau_{\theta}}{\mathrm{d} \theta}=\frac{\mathrm{F}}{\mathrm{A}} \cos 2 \theta=0 \\
& \begin{array}{ll}
\text { Leading to } & \cos 2 \theta=0 \\
\text { or } & \theta=45^{\circ}\left(\text { or } 135^{\circ}\right)
\end{array}
\end{aligned}
$$

i.e., Maximum shear $\left(\tau_{\theta \max }\right)$ occur at $\theta=45^{\circ}$ with this following value

$$
\tau_{\theta \max }=\frac{\mathrm{F}}{2 \mathrm{~A}}
$$

\section{MATERIALS AND METHODS}

A compressive-shear head apparatus made from Aluminum solid blocks with interchangeable ram heads was designed and constructed. Six pairs of the ram heads were prepared. Each pair had the contacting inclined surface at an angle $\theta$ with respect to a horizontal plane of $0^{\circ}, 15^{\circ}, 30^{\circ}, 45^{\circ}, 60^{\circ}$ and $70^{\circ}$, respectively. This apparatus was used in conjunction with a universal testing machine (UTM). Whereby the vertical load $F$ was exerted under a measurable recording data of the software program integrated in the UTM. The experiment was conducted by placing a single grain of rice to be rested on the incline surface between the pair of a ram head. The ram head were seated in the Aluminum block, which was confined only vertical movement of the ram head. By controlling the vertical movement of the bulkhead of UTM at 5 $\mathrm{mm} / \mathrm{min}$ hence the load $\mathrm{F}$ was recorded until fracture of the specimen.

A single grain of rice, either rough rice or a brown rice was placed with its natural posture so that thickness 
(h) is normal to the inclined surface. Two arrangements were made such that if the length (L) parallel to the incline surface is defined as a parallel grain position (Fig. 3). If the length (L) of the grain is perpendicular to the incline surface, is defined as a cross grain position accordingly (Fig. 4).

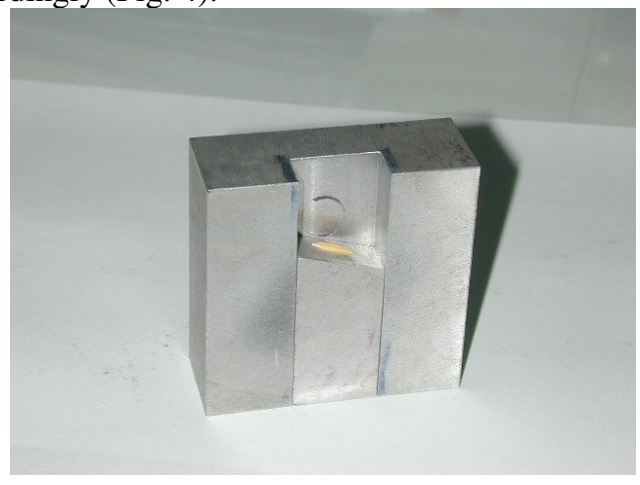

Fig. 3: A parallel grain position

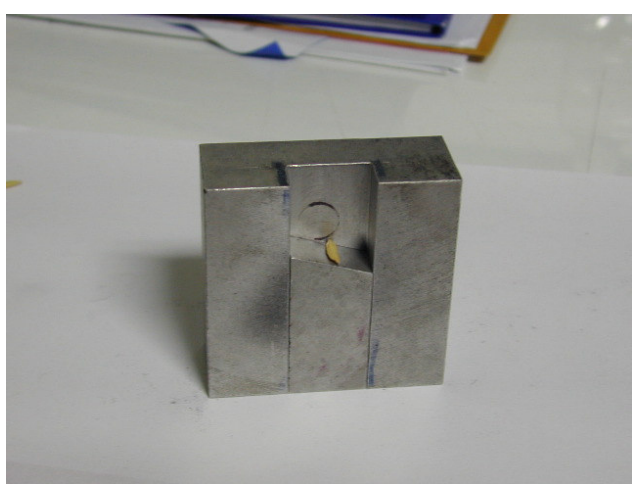

Fig. 4: A cross grain position

All the rough rice was handpicked, at the harvesting season from the Sanpatong rice experiment station. Then it was placed in natural ventilated condition to ensure that the specimens were reached their natural equilibrium of moisture with minimum residual stress in the grain. Six varieties of rice were selected for this experiment: RD2 (short grain, Japonica), Sanpatong (glutinous, Indica), Pathumtanee (long grain and non-glutinous, Indica), Dokmali105 (Khao-dokmali 105) or Jusmin105 (long grain and nonglutinous, Indica), Khamnai (highland-draught resistance, long grain and non-glutinous, Indica) and Supanburi (hybrid of Dokmali105, long grain and nonglutinous, Indica). Prior to the experiment, each variety was carefully inspected; only 90 rough rice and healthy one were selected. Other equal numbers of 90 were peeled off its husk by hand as the test specimens of brown rice. Fifteen replica of the test were conducted for each variety, both rough and brown rice. Direct result so obtained from the UTM was relationship of the compressive load $\mathrm{F}$ with respect to deformation length. Of which showed the characteristic of abrupt loss of the load at the fracture of the specimen. Considered as a brittle type of specimen, therefore the maximum compressive load is the ultimate yield point.
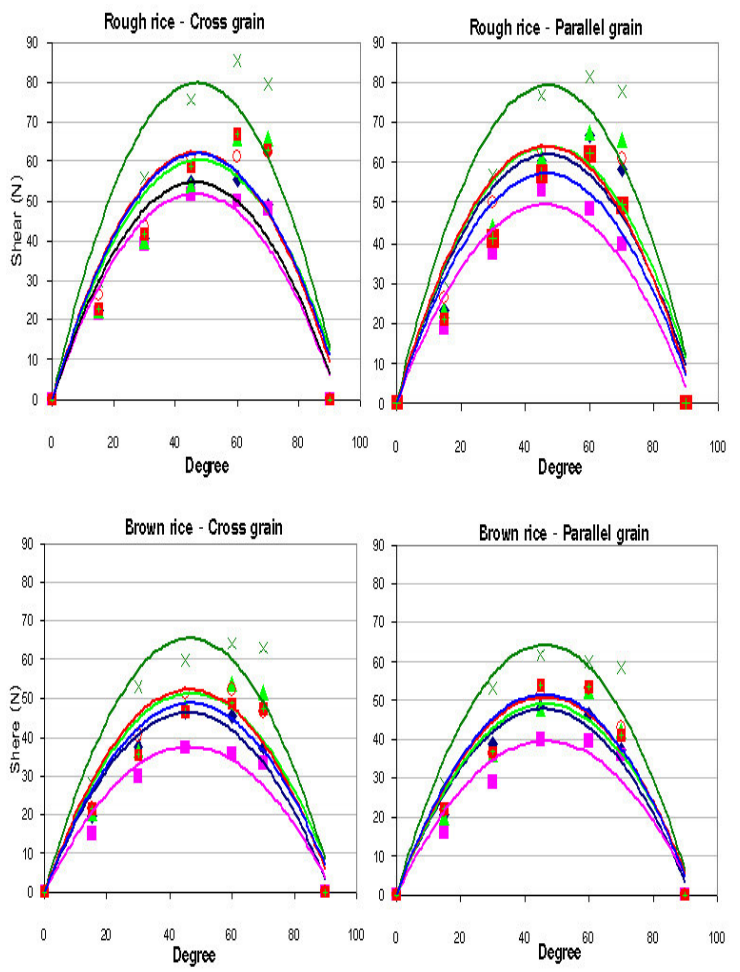

- Dokmali105 Khamnhai $\Delta$ Pathumtanee $\times$ Supanburi OSanpatong $\mathbf{E R D} 2$

Fig.5: Shear strength with respect to shear angle of 6 varieties of rice (Each data point represent of 15 replicates)

Depending upon the value of $\theta$ set by the ram head and the value of force $F$, then by equation (3) the maximum shear force $\mathrm{T}$ causes breakage of the grain can be evaluated.

\section{RESULTS AND DISCUSSION}

Fifteen values of the maximum shear force $\mathrm{T}$ obtained from each particular type of rough or brown rice, at any selected ram head of a certain $\theta$. Therefore each rice variety either rough or brown rice, one can obtain 90 pairs of the maximum shear $\mathrm{T}$ with respect to the angle $\theta$. Add further with 2 boundary conditions that, if $\theta=0^{\circ}$ and $90^{\circ}$ then the value of $\mathrm{T}=0$. Hence, total numbers of 92 of $\mathrm{T}$ with respect to $\theta$ were plot for each type of rice. Consequently regression line was 
Am. J. Agri. \& Biol., 3(1): 325-329, 2008

Table 1: Shear resistance of rice grain with respect to shear angle of 6 rice varieties (Each regression equation derived from 92 measured data)

\begin{tabular}{|c|c|c|c|}
\hline $\begin{array}{l}\text { Rice Varieties } \\
\text { and Experiment types }\end{array}$ & $\begin{array}{l}\text { Equations of } \\
\text { regression lines ( } \mathrm{T} \text { versus } \theta \text { ) }\end{array}$ & R-square $\left(\mathrm{R}^{2}\right)$ & $\begin{array}{l}\text { Calculated maximum shear } \\
\mathrm{T} \text { (Newton) at } \theta=45^{\circ}\end{array}$ \\
\hline Dokmali105, Rough, Cross grain & $\mathrm{T}=-0.0254 \theta^{2}+2.3596 \theta$ & 0.9298 & 54.75 \\
\hline Dokmali105, Rough, Parallel grain & $\mathrm{T}=-0.0282 \theta^{2}+2.641 \theta$ & 0.8886 & 61.74 \\
\hline Dokmali105, Brown, Cross grain & $\mathrm{T}=-0.022 \theta^{2}+2.0167 \theta$ & 0.9674 & 46.20 \\
\hline Dokmali105, Brown, Parallel grain & $\mathrm{T}=-0.0227 \theta^{2}+2.0807 \theta$ & 0.9723 & 47.66 \\
\hline Khamnai, Rough, Cross grain & $\mathrm{T}=-0.0241 \theta^{2}+2.2351 \theta$ & 0.9332 & 51.78 \\
\hline Khamnai, Rough, Parallel grain & $\mathrm{T}=-0.0234 \theta^{2}+2.1494 \theta$ & 0.9445 & 49.34 \\
\hline Khamnai, Brown, Cross grain & $\mathrm{T}=-0.0175 \theta^{2}+1.6212 \theta$ & 0.9464 & 37.52 \\
\hline Khamnai, Brown, Parallel grain & $\mathrm{T}=-0.0183 \theta^{2}+1.7036 \theta$ & 0.9247 & 39.60 \\
\hline Pathumtanee, Rough, Cross grain & $\mathrm{T}=-0.0265 \theta^{2}+2.5268 \theta$ & 0.8203 & 60.04 \\
\hline Pathumtanee, Rough, Parallel grain & $\mathrm{T}=-0.0287 \theta^{2}+2.7147 \theta$ & 0.8622 & 64.04 \\
\hline Pathumtanee, Brown, Cross grain & $\mathrm{T}=-0.0232 \theta^{2}+2.184 \theta$ & 0.8787 & 51.30 \\
\hline Pathumtanee, Brown, Parallel grain & $\mathrm{T}=-0.0227 \theta^{2}+2.1096 \theta$ & 0.9237 & 48.96 \\
\hline Supanburi, Rough, Cross grain & $\mathrm{T}=-0.036 \theta^{2}+3.3886 \theta$ & 0.8745 & 79.59 \\
\hline Supanburi, Rough, Parallel grain & $\mathrm{T}=-0.0361 \theta^{2}+3.3838 \theta$ & 0.8937 & 79.17 \\
\hline Supanburi, Brown, Cross grain & $\mathrm{T}=-0.0303 \theta^{2}+2.819 \theta$ & 0.9214 & 66.50 \\
\hline Supanburi, Brown, Parallel grain & $\mathrm{T}=-0.0302 \theta^{2}+2.7868 \theta$ & 0.9551 & 64.25 \\
\hline Sanpatong, Rough, Cross grain & $\mathrm{T}=-0.0283 \theta^{2}+2.6495 \theta$ & 0.8925 & 61.92 \\
\hline Sanpatong, Rough, Parallel grain & $\mathrm{T}=-0.0298 \theta^{2}+2.7642 \theta$ & 0.9295 & 64.04 \\
\hline Sanpatong, Brown, Cross grain & $\mathrm{T}=-0.0244 \theta^{2}+2.2591 \theta$ & 0.9404 & 52.25 \\
\hline Sanpatong, Brown, Parallel grain & $\mathrm{T}=-0.0237 \theta^{2}+2.1965 \theta$ & 0.9316 & 50.85 \\
\hline RD2, Rough, Cross grain & $\mathrm{T}=-0.0277 \theta^{2}+2.6148 \theta$ & 0.8586 & 61.57 \\
\hline RD2, Rough, Parallel grain & $\mathrm{T}=-0.0265 \theta^{2}+2.463 \theta$ & 0.9092 & 57.17 \\
\hline RD2, Brown, Cross grain & $\mathrm{T}=-0.0223 \theta^{2}+2.0801 \theta$ & 0.9090 & 48.45 \\
\hline RD2, Brown, Parallel grain & $\mathrm{T}=-0.0243 \theta^{2}+2.2387 \theta$ & 0.9374 & 51.53 \\
\hline
\end{tabular}

Table 2: Shear resistance of rice husk skin

\begin{tabular}{lccc} 
Table 2: Shear resistance of rice husk skin & $\begin{array}{c}\text { Probable maximum shear } \\
\text { resistance due to husk skin } \\
\text { Rice varieties }\end{array}$ & $\begin{array}{c}\text { Probable minimum shear } \\
\text { resistance due to husk skin } \\
\mathrm{T}_{\text {husk }}^{\text {max }} \text { (Newton) }\end{array}$ & $\begin{array}{c}\text { Range of probable shear } \\
\text { resistance due to husk skin }\end{array}$ \\
\hline Dokmali105 & 15.54 & 7.09 & $\Delta \mathrm{T}_{\text {husk }}^{\text {min }}$ (Newton) \\
Khamnai & 14.26 & 9.74 & 8.45 \\
Pathumtanee & 15.08 & 8.74 & 4.52 \\
Supanburi & 15.34 & 12.67 & 6.34 \\
Sanpatong & 13.46 & 9.67 & 2.67 \\
RD2 & 13.12 & 5.64 & 3.97 \\
Average values & 14.47 & 8.93 & 7.48 \\
(Standard deviation) & $(1.02)$ & $(2.43)$ & 5.57 \\
\hline
\end{tabular}

drawn to best fit with these clusters of data. With another restrained in particular that the peak must be at the vicinity of $\theta \approx 45^{\circ}$. The plot of all six rice varieties are shown into 4 groups, i.e. the rough rice with cross grain, the rough rice with parallel grain, the brown rice with cross grain and the brown rice with parallel grain. Figure 5 combined the 4 groups of plot altogether for comparison. It reveals that raw data tested from all rice varieties of each particular experiment were significantly being fit with similar trend or regression curves. All the curves were forced to fit well under the aforementioned criteria. Table 1 shows all information of curves fitting. Included in the table is the $4^{\text {th }}$ column of calculated values of maximum shear T at $\theta=45^{\circ}$.

Scrutinize the calculated values of maximum shear (T) at $\theta=45^{\circ}$ shown in Table 1 , one can distinguish the variation of values. Disregard the cross or parallel grain orientations, for each particular rice variety offers significant characteristics as following definitions,

\footnotetext{
$\mathrm{T}_{\text {husk }}^{\max }=$ Maximum rough rice shear - Minimum brown rice shear (7)

$\mathrm{T}_{\text {husk }}^{\mathrm{min}}=$ Minimum rough rice shear - Maximum brown rice shear (8)
} 
and $\quad \Delta \mathrm{T}_{\text {husk }}=\mathrm{T}_{\text {husk }}^{\max }-\mathrm{T}_{\text {husk }}^{\min }$

Description for $\mathrm{T}_{\text {husk }}^{\max }, \mathrm{T}_{\text {husk }}^{\min }$ and $\Delta \mathrm{T}_{\text {husk }}$ are shown in Table 2 correspondingly.

\section{ACKNOWLEDGEMENTS}

The authors gratefully acknowledge the University Bureau of Thailand for equipment support and the Faculty of Engineering, Chiang Mai University for financial sustenance. The authors also thank Sanpatong Rice Experiment Station, Department of Agriculture for providing rice grains.

\section{Nomenclature}

UTM = universal testing machine

$\mathrm{N}=$ normal force component

$\mathrm{T}=$ tangential force component

$\mathrm{L}=$ grain length

$\mathrm{h}=$ length of awn or beard

$\sigma_{\mathrm{n} \theta}=$ normal stress

$\tau_{\theta}=$ shear stress

$\tau_{\theta \max }=$ maximum shear stress

\section{REFERENCES}

1. Department of Agriculture, 1988. Manual of Rice Data Base. Rice Research Institute, Bangkok, pp: 52 (In Thai).

2. Ministry of Commerce, 1997. Announcement of Rice Standard B.E. 2540. Ministry of Commerce, Bangkok, pp: 142 (In Thai).

3. Chaitep, S., 1998. Analytical of causes of rice breakage in the rice mill prosesses. Chiang Mai University research fund. (Report in Thai), pp: 18.

4. Prongsiriwattana, C., 1991. General Information of Rice. Rice Research Institute, Bangkok, pp: 150 (In Thai).

5. Gariboldi, F., 1974. Rice Milling Equipment Operation and Maintanance. FAO, Rome, p: 1-24.

6. Juliano, O.B, 1986. Rice Chemistry and Technology. The American Association of Cereal Chemists : USA. p 349 - 373. 